\title{
A OCORRENCIA DE RIQUETSIOSES DO GRUPO RICKETTSIA RICKETTSII
}

Dalva A. Portari Mancini *

Elvira M. Mendes Nascimento*

Valéria Rósa Tavares*

Murillo Adelino Soares*

\begin{abstract}
MANCINI, D.A.P. et al. A ocorrência de riquetsioses do grupo Riekettsia rickettsii. Rev. Saúde públ., S. Paulo, 17:493-9, 1983.

RESUMO: Foi realizada revisão da literatura com objetivo de atualizar as informações sobre a ocorrência de riquetsioses do grupo Rickettsia rickettsii. Verificou-se que nos EUA e Europa, a incidência da febre maculosa, vem aumentando desde 1970 até hoje. No Brasil, foi relatado um caso presuntivo, no estado da Bahia, em 1979. Com relação a prevenção, controle e tratamento dessa doença é salientada a importância de informações relacionadas com individuos expostos a picadas de carrapatos, notificação de novos casos, fatores ecológicos, técnicas laboratoriais mais específicas para a identificação do agente etiológico, e a antibioticoterapia mais eficiente. A vacinação é ainda referida como meio mais favorável na prevenção da doença, devendo ser administrada aos indivíduos de alto risco. No Brasil, faltam informaçōes precisas sobre a ocorrência de $\mathbf{R}$. rickettsii.
\end{abstract} rência.

UNITERMOS: Riquetsioses. Rickettsia rickettsii. Febre maculosa, ocor-

\section{OCORRENCIA}

O aumento de casos de febre maculosa nos EUA tem sido observado a partir de 1970, tendo, em 1977 se estabilizado. Sua ocorrência nos Estados do sul e a alta incidência em jovens do sexo masculino $\mathrm{e}$ de côr branca tem permanecido inalterada nos últimos tempos ${ }^{18}$.

Magnarelli e col.10, analisando a incidência da febre maculosa das Montanhas Rochosas em Connecticut, revisaram dados clínicos de casos humanos suspeitos, ocorridos em 1965-1977. Houve seis casos presuntivos nesse período provavelmente originados em Connecticut, sendo que quatro desses casos ocorreram em áreas onde 0 carrapato vetor Dermacentor variabilis é abundante. As riquétsias do grupo da febre maculosa estão presentes em baixa freqüiencia tanto em regiōes do interior, como na regiăo costeira de Connecticut. Essa situação é diferente da que ocorre nas proximidades de Long Island, onde 124 casos humanos foram documentados no periodo de 1971-1976 e onde a freqüência de carrapatos infectados com riquétsias é maior. Possivelmente, devido a fatores ecológicos desconhecidos, fạcos endêmicos não se perpetuam de um ano para outro em Connecticut. Isto parece indicar que a Rickettsia rickettsii não está bem estabelecida lá, como em Long Island e outras regiōes

\footnotetext{
* Do Serviço de Virologia do Instituto Butantan - Av Vital Brasil, 1.500 - 05503 - São Paulo, SP - Brasil.
} 
MANCINI, D.A.P. et al. A ocorrência de riquetsloses do grupo Rickettsia rickettsii. Rev. Saude públ., S. Paulo, 17:493-9, 1983.

mais ao sudeste. Presumindo-se que estes agentes venham acentuar a sua presença em populações de roedores de Connecticut, poder-se-ia esperar aumento correspondente da prevalência de casos humanos.

Foi também observado o ressurgimento da febre maculosa, na Europa, na cidade de Sassari, Itália, e na cidade de Sabadell (provincia de Barcelona), Espanlı, no periodo de 1978-1980. Essa situação assemelha-se a de outras áreas geográficas onde a doença é endêmica. Admite-se que a reincidência urbana da febre maculosa, deve-se ao fato do aumento do número de animais domésticos, nessas cidades ${ }^{20}$.

Na primeira metade da década de 70 , durante estudos de focos naturais ativos de riquetsioses do grupo da febre maculosa, na Checoslováquia, foram isoladas riquétsias em carrapatos, mosquitos e piolhos e detectados anticorpos com riquétsias em diversas espécies de animais silvestres e domésticos, além de seres humanos ${ }^{13}$.

A presença presuntiva da febre maculosa, no Brasil, foi relatada em Salvador, em 1979. É um fato de acentuada importância por ser o primeiro caso publicado no Estado da Bahia, pois antes a incidência se limitava ao Estado de São Paulo, sul do Estado de Minas Gerais e norte do Estado do Paraná. Isto sugere a distribuição geográfica da doença no Brasil, mais ampla do que se conhecia anteriormente. $O$ caso observado sugere ainda que, ou a febre maculosa pode apresentar um quadro clínico distinto daquele descrito nos textos, ou que existem na região outras riquétsias do grupo, até agora não identificadas. Devido ao fato de não ter sido identificada a riquétsia responsável pela doença, torna-se difícil afirmar que $o$ agente causal foi a $R$. rickettsii, a única até agora identificada nas Américas ${ }^{15}$.

Em 1981, um total de 1.170 casos de febre maculosa ocorridos nos EUA foi constatado pelo CDC 18,19 (Center for Disease Control, Atlanta, Georgia), com incidência de 0,51 casos por 100.000 habitantes. Os Estados do Atlântico Sul soma- ram 671 casos ou $57 \%$ do total. A maior incidência coube à Carolina do Norte com 301 casos, seguido por Virginia, 105 casos, Larolina do sul, 102 casos, Uklahoma, 99 casos, lennensee, 82 casos, Maryland, 66 casos e Arkansas, 35 casos. Destes pacrelites $60 \%$ eram do sexo masculino, menores ue 20 anos de idade, e $92 \%$ eram brancos, embora os casos fatais fossem predominantes em negros, em individuos maiores de 30 anos de idade e que não tinham recebido tratamento imediato, por não apresentarem marcas de picadas de carrapato.

Em 1982, foi relatado um caso de febre maculosa, durante o inverno, em uma àrea endêmica da cidade de Carolina do Norte, mostrando que essa doença não é exclusiva de verăo (quando há maior ocorrência de carrapatos).

\section{EPIDEMIOLOGIA}

A epidemiologia da febre maculosa não está bem definida no relacionamento população humana e de carrapatos infectados. Linnermann e col. ${ }^{9}$, em estudos realizados nesse sentido em Clermont, Ohio, USA, revelaram que a incidência de riquétsias em carrapatos $D$. variabilis era aproximadamente a mesma tanto em área endêmica (de $1.168,18$ infectados, ou seja, $1,5 \%$ ) como em áreas não endêmicas (de 339, 4 infectados, ou seja, $1,2 \%)$.

O futuro da febre maculosa em áreas endêmicas tais como no municipio de Clermont, Ohio, pode ser prognosticado, isto é, com o resultado do crescimento da população suburbana, o "habitat", do carrapato é destruído, e com isso espera-se um decréscimo da incidência da doença. Porém, de qualquer maneira, como a área metropolitana é de contínuo crescimento, novas áreas endêmicas poderão surgir nas extremidades de suburbanização. Em Long Island, no períoco em 1971 a 1976, foi verificado o aumento de casos de febre maculosa, tanto em área endêmica, como em 
MANCINI, D.A.P. et al. A ocorrência de riquetsioses do grupo Rickettsia rickettsii. Rev. Saúde publ., S. Paulo, 17:493-9, 1983.

não endêmica, associando-se este fenômeno com a suburbanizaçao ${ }^{1}$. Iva Lalıtorma, região onde o vetor clássico Dermacentor andersoni não existe, esporadicamente ocorrem casos de febre maculosa, e pouco se sabe sobre o vetor patogênico hospedeiro. De 1974 a 1979 foi estudado o potencial de hospedeiros vertebrados (coelhos, cangurus e camundongos) e de carrapatos vetores de riquétsıás do grupo da febre maculosa. Titulos significantes de anticorpos foram detectados em diversas espécies desses vertebrados pelo método de fixação de complemento e imunofluorescência indireta. Um total de 4.485 carrapatos, compreendendo 8 espécies diferentes, estavam infectados com riquétsias, indicando que existem carrapatos vetores de riquétsias do grupo da febre maculosa, de espécies diferentes da $D$. andersoni, e que são encontrados, também, em outras regiões dos EUA ${ }^{7}$.

No Brasıl, não há estudos recentes sôbre a presença de $R$. rickettsii, no vetor brasileiro, o carrapato Amblyoma cajennense e, nem tão pouco, em outras espécies de carrapatos.

\section{ASPECTO CLINICO}

Os animais usados para testes (cobaias), quando inoculados com $R$. rickettsii, não recebendo tratamento, morrem de 9 a 10 dias após a inoculação, e os animais que se mostram mais resistentes e que por este motivo tem uma prolongada sobrevivência, apresentam severas lesões, tais como: necrose escrotal, enfartamento de orelha, entumecimento, e hemorragias perivasculares e das patas.

Os animais tratados com antibióticos apresentam citonecrose, trombose, deposição extravascular de fibrina, provenientes de células inflamatórias com fagocitose polimorfonuclear de riquétsias e produção de anticorpo específico ${ }^{23}$.

Em seres humanos a doença clínica é caracterizada por um ataque inesperado de dores de cabeça (sensação de frio, febre, mialgias e erupçōes na pele, principalmente no tronco, palma das mãos e sola dos pés $2,5,16,18,18$.
Devido ao fato de não se saber da exposiçao ao carrapato e ainda o tardio aparecimento de erupçảo na pele, acompaninado de implicaçōes gastrointestinais, os casos fatais sao muto freqüentes ${ }^{19}$.

\section{TRANSMISSÃO}

Além da transmissão natural pelo carrapato infectado, é conhecida a infecção por exposição a aerossóis de material contaminado em laboratórios e a transmissão entre seres humanos através da transfusão de sangue $2,5,22,24$.

Os carrapatos, usualmente, só transmitem o agente etiológ1co após permanecerem fixados por aigumas horas na pele do indvíduo.

Portanto, devem ser removidos tão logo se perceba e para removê-los é preciso o auxílio de uma pinça, para árrancá-los lenta e firmemente. A remoção de carrapatos com as mãos desprotegidas de luvas, pode causar infecção em virtude da secreção contaminada eliminada por eles e de qualquer maneira as mãos deverão ser lavadas, minuciosamente, com água e sabão, após'a operação đa extração ${ }^{18,19}$.

\section{DIAGNOSTICO - METODOS PARA DETECÇÃO DE RIQUETSIAS}

As informações clínicas nem sempre são suficientes para identificação de agentes etiológicos e diagnóstico de doenças infecciosas e, por este motivo, a elas são associadas provas de laboratório para o diagnóstico e confirmação. No caso de febre maculosa, o diagnóstico associado a provas de laboratório, não é possível antes do $10^{\circ}$ e $14{ }^{\circ}$ dia do contágio. $O$ diagnóstico pelo método de Weil-Felix (Proteus OX-19 ou OX-2) poderá indicar apenas se se trata de um caso provável de febre maculosa. Os casos diagnosticados clinicamente só podem ser confirmados quando o diagnóstico laboratorial específico (métodos de imunofluorescência, hemaglutinação indireta ou aglutinação de latex) detectar no soro do 
MANCINI, D.A.P. et al. A ocorrência de riquetsioses do grupo Rickettsia rickettsit. Rev. Saúde públ., S. Paulo, 17:493-9, 1983.

paciente título de anticorpos considerado positivo $4,7,9,14,16,19,21$. Individuos dos quais o agente causador é isolado de biópsias ou autópsias, ou que possua anticorpos positivos no teste de imunofluorescência; também são considẹrados casos positivos \$6,19.

A identificação de riquétsias em cobaias moribundas infectadas pode ser feita em cortes histológicos, de fígado e baço, por técnicas de imunofluorescência e de microscopia eletrônica ${ }^{23}$. Também são realizados exames de carrapatos infectados com riquétsias da febre maculosa, por testes de hemolinfa e análises de soros de mamíferos, quanto a presença de anticorpos contra $R$. rickettsii ${ }^{10}$.

Recentemente, foram aplicados para a detecção de riquetsioses, testes imunoenzimáticos (Elisa) ${ }^{3,11}$.

$O$ isolamento de riquétsias torna-se mais difícil quando já se realizou a vacinação ou a antibioticoterapia no paciente.

\section{TRATAMENTO}

Tetraciclina e cloranfenicol são riquetsiostáticos que permanecem efetivos no tratamento da febre maculosa, principalmente se a terapia for iniciada na primeira semana da doença $2,5,6,16,18,19$. O laurilsulfato de tetraciclina, um derivado lipossolúvel de tetraciclina, foi avaliado como satisfatorio no tratamento de febre maculosa, por que tem tendência a normalização mais rápida da temperatura. Embora deva ser confirmado por estudos posteriores, os primeiros resultados obtidos com este antibiótico permitiram acrescentar uma nova terapêutica substitutiva aquela clássica empregada no tratamento da febre maculosa, proporcionando vantagens pela boa tolerância local por via intramuscular e a possibilidade de aplicação a intervalos longos (cada 12 ou 24 horas) ${ }^{21}$.

\section{PREVENÇÃO - DESENVOLVIMENTO DE VACINAS CONTRA A FEBRE MACULOSA}

As vacinas contra a febre maculosa foram preparadas inicialmente em 1929, com suspensão fenolizada de carrapatos infectados com $R$. rickettsii, e foram substituidas poste. rormente pelas vacinas preparadas com riquétsias cultivadas em membranas vitelinas de ovos férteis de galinha e inativadas pelo formoldeido. Devemoś ressaltar o pioneirismo do Instituto Butaritan, na produção destas vacinas, iniciadas pelos pesquisadores J. Lemos Monteiro, J. Travasso e A. Avallejo Freire 2,5,12,22. Até 1975 estas duas vacinas foram utilizadas para proteção de seres humanos embora ambas comumente induziam eritema local na regiăo de inoculação, predominantemente após a segunda ou terceira doses da vacina. Apenas a vacina proveniente de membranas vitelinas permaneceu por ser mais eficaz e mais pura do que a original de carrapatos. As vacinas inativadas são protetoras, modificando a doença, embora às vezes falhando $2,5,16$. O Instituto Butantan mantém pequeno estoque desta vacina para eventualidades e está aparelhado para produzir maior quantidade, se necessário.

Através de experimentos com riquétsias cultivadas em culturas de células primárias de embrião de pato (CEP), verificou-se alta infectividade, embora a virulência em cobaias a a toxidade em ratos tivessem sido perdidas durante as primeiras passagens. A virulência foi recuperada imediatamente quando propagadas, em seguida, em ovos embrionados de galinha. Constatou-se que riquétsias cultivadas em CEP e inativadas pelo formoldeido ou raios gama $\left(5 \times 10^{5} \mathrm{r}\right)$ produziram vacinas com alto poder antigênico ${ }^{6}$. Este fato propiciou o preparo de vacinas contra a febre maculosa para imunização humana, utilizando riquétsias cultivadas em células de embrião de galinha "in vitro" com bom rendimento $16,17,25$, e ainda conferindo proteção contra outras cepas, além da $R$. rickettsii.

O preparo da vacina em cultura de células embrionárias é mais complexo do que o da vacina de membrana vitelina, comercialmente utilizada no presente, mas tem vantagens como o prolongamento do período de incubação e diminuição da reincidência a da infecção '. 
MANCINI, D.A.P. et al. A ocorrência de riquetsioses do grupo Rickettsia rickettsii. Rev. Saúde públ., S. Paulo, 17:493-9, 1983.

Tendo em vista que a vacina contra a febre maculosa não é produzida em grande escala comercial, sugere-se o preparo em culturas celulares (maior grau de potência e de pureza) e recomenda-se sua utilização em populações de alto risco, isto é, manipuladores de riquétsias em laboratórios, dedetizadores de matas e residentes em zonas endêmicas $2,5,16$.

\section{CONTROLE}

Programas educacionais a respeito de carrapatos e sua ação na epidemiologia da febre maculosa são de grande importância para o controle desta doença ${ }^{9}$.

A importante mudança na metodologia de controle da febre maculosa, nos EUA, em 1981, foi a adoção de informações sobre novos casos, com auxílio dos relatos sobre sintomas, hospitalização, tratamento, exposição a carrapatos, identificação do carrapato vetor, viagens para zonas endèmicas e definição de critérios rigorosos para a confirmação de casos através de testes laboratoriais. Esses critérios adotados em 1981 foram responsáveis pela redução de casos. Isto mostra que a confirmação de casos prováveis, através de vigilância epidemiológica rigorosa e de recursos laboratoriais, é de extrema importância, uma vez que a manifestação clínica da doença é tardia (de pelo menos 10 dias). O controle da febre maculosa será mais eficiente, quanto mais informaçōes houver de individuos expostos a carrapatos 18.19 .

É, também, muito importante a ação contra o vetor artrópode, e isto consiste na pulverização de inseticida em tocas de ratos e no tratamento de cães e outros animais domésticos portadores de carrapatos. Os repelentes também podem ser usados contra os mesmos.

\section{CONCLUSÁO}

Baseados nas informações sobre o aumento de casos de febre maculosa, nos EUA e Europa, desde 1970 até hoje, conclui-se que não se trata de doença erradicada, mas razáo de preocupação para as autoridades responsáveis pela vigilância epidemiológica.

O esclarecimento da situação atual da febre maculosa, nos EUA, deve-se aos recentes trabalhos sobre a presença de $R$. rickettsii nos carrapatos vetores $D$. andersoni e $D$. variabilis, tanto em zona endêmica como não-endêmica e ainda aos estudos estimativos da ocorrência de casos humanos em diversos Estados do pais, constatando-se prevalência para o Estado de Carolina do Norte.

Receia-se que a situação da ocorrência desta riquetsiose no Brasil não seja muito diferente daquela dos EUA, tendo em vista ser o mesmo agente etiológico ( $R$. rickettsii), e áreas geográficas com características semelhantes que podem manter o equilibrio ecológico do vetor. Porém, torna-se difícil esclarecer a situação no Brasil, pois faltam dados, isto é, não há estudos recentes sobre a existência de $R$. rickettsii no vetor brasileiro clássico, o carrapato Amblyoma cajennense. E nem, tampouco, registros de casos, com exceção de um provável, no Estado da Bahia, que por falta de recursos especializados não foi possivel identificar o agente etiológico, baseando-se a confirmação apenas na sintomatologia do paciente.

Podemos concluir sugerindo que deve ser mantida uma vigilância epidemiológica constante e rigorosa e todos os casos suspeitos serem diagnosticados em laboratórios especializados para confirmação.

A ausência dos recursos preventivos citados e de laboratórios especializados para diagnóstico poderá trazer surpresas desagradáveis se ocorrer algum surto epidêmico. 
MANCINI, D.A.P. et al. A ocorrência de riquetsioses do grupo Rickettsia rickettsii. Rev. Saúde públ., S. Paulo, 17:493-9, 1983.

MANCINI, D. A. P. et al. [Occurrence of rickettsiosis of the group Rickettsia rickettsii]. Rev. Saúde públ., S. Paulo, 17:493-9, 1983.

ABSTRACT: A search of the literature to update the available information on the occurrence of rickettsiosis caused by the Rickettsia rickettsii group was made. It was verified that the incidence of spotted fever has had an increase in the U.S.A. and Europe since 1970. In Brazil, a presumptive case was reported in the State of Bahia, in 1979. Regarding the prevention, control and treatment of this disease, importance is given to data related to individuals exposed to tick bites, report of new cases, ecological factors, more specific laboratorial procedures for the identification of the etiological agent, and a more efficient antibiotic therapy. Vaccination is still regarded as the most adequate means for the prevention of the disease, and should be aimed at groups of individuals at high risk. In Brazil, there is a lack of more precise information on the occurrence of $R$. rickettsii.

UNITERMS: Rickettsial infections. Rickettsia rickettsii. Rocky mountain spotted fever, occurrence.

\section{REFERENCIAS BIBLIOGRAFICAS}

1. BENACH, J.L.; WHITE, D.J.; BURGDURFER. W., KEELAN, T.; GUIRGIS, S. \& ALTIERI, R.H. Changing patterns in the incidence of Rocky Mountain Spotted Fever on Long Island, Amer. $J$. Epidem., $106: 380-7,1977$.

2. CALIA, F.M.: BARTELLONI, P.J. MICKNNEY, R.W. RMSF-Laboratory infection in a vaccinated individual, $J$. Amer. med. Ass., 211:2.012-4, 1970.

3. HALLE, S. \& GASH, G.A. Use of a sensitive microplate enzyme like inmusorbent assay in a retrospective serological analysis of a laboratory population at risk to infection with typhus group rickettsial $J$. clin. microbiol., 12:343-50, 1980 .

4. HECHEMY, K.E.; ANACKER, P.L.; PHILIP, R.N.; KLEMAN, K. T.; Mac-CORMACK, J.N.; SASOWSKI, S.J. \& MICHAELSON, E.E. Detection of Rocky Mountain Spotted Fever antibodies by a latex agglutination test. $J$. clin. Microbiol., 12:144-50, 1980 .

5. KENYON, R.H. \& PEDERSEN Jr., C.E Preparation of Rocky Mountain Spotted Fever vaccine suitable for human immunization. $J$. clin Microbiol, 1:500-3. 1975 .

6. KENYON, R.H. \& PEDERSEN Jr., C.E. Preparation of vaccines of Rocky Moun- tain Spotted Fever from Rickettsiae propagated in cell culture. $J$. infect. Dis., $\tilde{5} 2: 125-46,1982$

7. LANE, R.S.: EMMONS, R.W.: DONDERO, D.V. \& NELSON, B.C. Ecology of tick-borne agents in California. Amer. $J$. trop. Med. Hyg., 30:239-52, 1981.

8. LANGE, J.V.; WALKER, D.H. \& WESTER, T.B. Documented RMSF in Wintertime. J. Amer, med. Ass., 247:2.403-4, 1982.

9. LINNEMANN Jr., C.C.: SCHAEFFER, A. E. ; BURGDORFER, W.; HUTCHINSON, L. \& PHILIP, R.N. RMSF in Clermont County, Ohio. Amer. J. Epidem., 111: $31-6, \quad 1980$.

10. MAGNARELLI, L.A.; ANDERSON, J.F. \& BURGDORFER, W. RMSF in Connecticut: human cases, Spotted-Fever group rickettsiae in ticks, and antibodies in mammals. Amer. J. Epidem.,110:148-55, 1979.

11. MANSUETO, S. \& MICELLI, M.D. ELISA and Rickettsioses. Trans, roy. Soc. trop. Med. Hyg., 74:831-2. 1980.

12. MONTEIRO, J.L. A vacinação preventıva como base da profilaxia do typho exanthemático de São Paulo. Mem. Inst. Butantan, 10:1-16, 1935/36. 
MANCINI, D.A.P. et al. A ocorréncia de riquetsioses do grupo Rickettsia rickettsii. Rev. Sande. puibl., S. Paulo, 17:493-9, 1983.

13. PALANOVA, J.R.; ZUPANCICOVA, M. ; URVOLGYI, J.; KOVACOVA, E.; JARABEK, L. \& BREZINA, R. Study of rickettsioses in Slovakia. J. Hyg. Epidem. Immunol., 1:105-15, 1975.

14. PHILIP, R.N.; CASPER, E.A.; MacCORMACK, J.N.; SEXTON, D.J.; THOMAS, L.A.; ANACKER, R.L.; BURGDORFER, W. \& VICK, S. A comparison of serologic methods for diagnosis of Rocky Mountain Spotted Fever. Amer. $J$. Epidem., 105:56-67, 1977.

15. PLANK, S.J.; TEIXEIRA, R.S. \& MILANESI, M.L. Febre maculosa em Salvador: descrição de um caso. Rev. méd. Bahia, 25:330-4, 1979.

16. RICKETTSIOSES: a continuing disease problem; WHO Working Group. Bull. Wld Hith Org., 60:157-64, 1982.

17. RIZZO, E.; TUCHYIA, H.N.; BRUNNER Jr., A.; PORTARI, D.A. \& SOUZA, C.M. Multiplication of Rickettsia rickettsii in primary cell cultures. Rev. Microbiol., 3:1-6, 1972.

18. ROCKY, Mountain Spotted Fever, United States, 1980. Mort. Morb. whly Rep., $30: 318-20,1981$.

19. ROCKY Mountain Spotted Fever, United States, 1981. Mort. Morb. wkly Rep., $31: 261-3,1982$.

20. SEGURA. F. \& FONT, B. Ressurgence of Mediterranean Spotted-Fever in Spain. Lancet, 2:280, 1982.
21. TIRIBA, A. da C.; GODOY, C.V.F. de; BRITO, T. de; JORDAO, F.M.; PENNA, D. de O. \& SoUZA, A.R.T. de Febre maculosa em São Paulo: resultados terapêuticos em alguns casos com laurilsulfato de tetraciclina. Rev. Inst. Med. trop. S. Paulo, 10:256-61, 1968.

22. TRAVASSOS, J. \& VALIEJO-FREIRE, A. Criação artificial de Amblyoma cajennense para o preparo da vacina contra a febre maculosa. Mem. Inst. Butantan, $18: 145-236,1944 / 1945$ :

23. WALKER, D.H.; HARRISON, A.; HENDERSON, F. \& MURPHY, F.A. Identification of $R$. rickettsii in a guinea pig: model by immunofluorescent and eletron microscopic techniques. Amer. J. Pathol, $86: 343-52,1977$.

24. WELLS, G.M.; WOODWARD, T.E.; FISET, P. \& HORNICK, R.B. RMSF caused by blood transfusion. J. Amer. med. Ass., 239:2.763-5, 1978 .

25. WISSEMAN Jr., C.L.: SDLINGER, E.A.: WADDELL, A.D. \& JONES, M.R. Infection cycle of $R$, rickettsii, in chicken embryo and L-929 cells in cultures. Infect. Immun., 14:1.052-64, 1976.

Recebido para publicą̧ão em 20/05/1983́ Aprovado para publicação em 01/09/198. 